\title{
Solar-Energy-Driven Upward Water Flow and Evaporation from a Water Table Through a Porous Material in a Cylindrical Conduit
}

\author{
Hisato ICHIKAWA*, Hirakazu SEKI*, and Shinichi TAKAMI** \\ (Graduate School of Natural Science and Technology, Kanazawa University, Kanazawa 920-1192, Japan
$* *$ School of Agriculture, Kinki University, Nara 631-8505, Japan
}

\begin{abstract}
"Solar Pump" is a new concept of solar still where water is distilled as well as transported by solar energy. In the water reservoir, a column of porous material is immersed, which absorbs and transmits water. Water thus transported along the water potential gradient evaporates at the end of the column where the solar radiation is absorbed. It is then recovered with a condensing cover. To examine the feasibility of this concept, simultaneous transportation of heat and moisture through the sand column from varying depths of water table under constant irradiance was examined. A mathematical model, based on Philip and de Vries (1957), predicted that the rate of evaporation from a uniform sand column is maximum when the water table is $0.1 \mathrm{~m}$ deep. This is because the water potential decreases with height from the water table, whereas the temperature increases with height. Experimental results partially supported such a prediction. The results also suggested that the evaporation rates from the surface of the sand column were slightly higher than that from the water table. Thus, the proposed method could be useful if a proper porous material is selected.
\end{abstract}

Key words: Evaporation rate, Heat and moisture transfer, Porous materials, Solar heat, Water recovery system.

\section{Introduction}

As fossil fuels become scarcer and the global environment degrades, the development of an efficient water recovery system operated with renewable energy is becoming increasingly important. The development of such an inexpensive water recovery system is particularly important for developing countries in arid and semi-arid regions where water shortage is acute.

The objective of this study is to develop a simple technology that uses porous materials and solar energy for purifying and transporting liquid solutions, such as sea water and lake water, where water pollution problems are obvious. Recently, Tanaka et al. (2007) reported a water treatment and recovery system that uses solar radiation. However, water recovery systems using porous materials have not been reported, except by Takami and Inaba (2000). They devised a watercollection system that uses a column packed with

Received; March 21, 2008.

Accepted; July 11, 2008. a porous material partially immersed in a reservoir of saline solution, thus allowing water to enter the column (Fig. 1). Water is transferred along the water potential gradient to the top of the column where it is evaporated by solar radiation energy. Water thus evaporated is collected as it condenses on the column cover. This system is called a "solar pump" because it is driven by solar energy and transports water from the reservoir to the place where it is condensed. The transportation mechanism of this system is similar to water transportation in plants through the xylem.

The rate at which water is transported and distilled with this system is determined primarily by the rate at which the water evaporates at the surface of the porous material. In this paper, we report some experimental results from a series of tests in which the upward flow of water from a water table through a sand column and evaporation from the upper surface of the column were examined in the laboratory. The results were analyzed using a mathematical model that describes the simultaneous transfer of heat and moisture. 


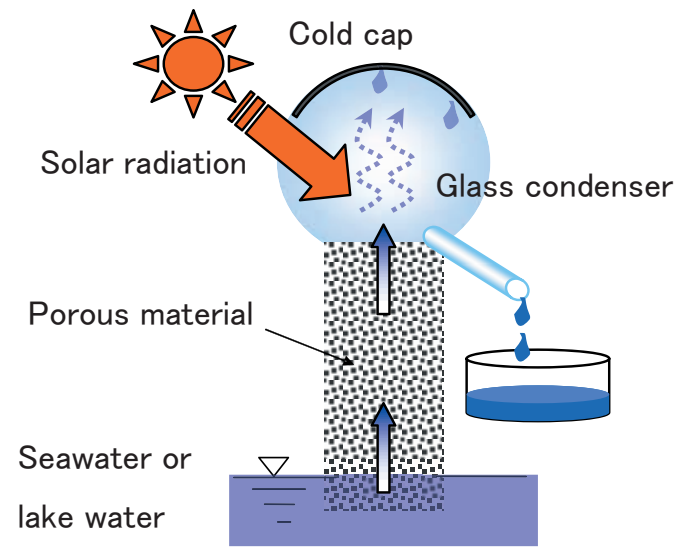

Fig. 1. Survey view of the proposed system.

\section{Materials and Methods}

\subsection{Experimental apparatus and method}

The main part of the experimental apparatus is an acrylic resin column of $50 \mathrm{~mm}$ diameter, $150 \mathrm{~mm}$ length, and $5 \mathrm{~mm}$ thickness (Fig. 2). The total length of the apparatus is $243 \mathrm{~mm}$, including a base made of PVC. River sand with a mean particle size of 0.5 $\mathrm{mm}$ was used as the porous material. Non-woven PVC cloth was placed at the bottom of the column, and $0.5 \mathrm{~kg}$ of sand was packed into it. The density of the sand particles was $2500 \mathrm{~kg} \mathrm{~m}^{-3}$, and the saturated volumetric moisture content was 0.43 . The moisture characteristic curve (Fig. 3) was obtained from the equation proposed by Matsuoka and Sohma (1983), in which parameters are determined by a curve-fitting technique using the preliminary experimental results for the matrix potential $\Phi_{p}$. Table 1 shows the experimental conditions.

The entire porous column was immersed in a water bath with a base of $200 \mathrm{~mm} \times 300 \mathrm{~mm}$ and a height of $243 \mathrm{~mm}$. Water was added to reach $135 \mathrm{~mm}$ below the top of the column and was kept for about $12 \mathrm{~h}$ until the column was saturated. The distance between the column surface and the water level in the reservoir was adjusted to be $10,50,100,120$, or $150 \mathrm{~mm}$ by adding water. A $100 \mathrm{~W}$ incandescent lamp was used as a radiation heat source. The height of the incandescent lamp was adjusted so that the radiative heat flux at the sand surface was controlled at $4860 \mathrm{~kJ} \mathrm{~m}^{-2} \mathrm{~h}^{-1}$.

$\mathrm{Cu}-\mathrm{Co}$ thermocouples were inserted into the sand at several positions: $20,30,40,60$, and $90 \mathrm{~mm}$ from the column surface along the vertical centerline of the column. The radiative heat flux $q_{\mathrm{r}}$ was measured with a universal analog photometer (LICOR, LI-185B).

Experiments were performed with the column either packed with sand or not packed with sand to investigate the effect of the presence of porous material on the water evaporation rates. The evaporation rates were determined by measuring the change in the total weight of the water reservoir and the porous column with time $t$. In all the experiments, the process reached a steady state within $24 \mathrm{~h}$, indicated by a constant temperature profile and evaporation rate. Measurements were taken

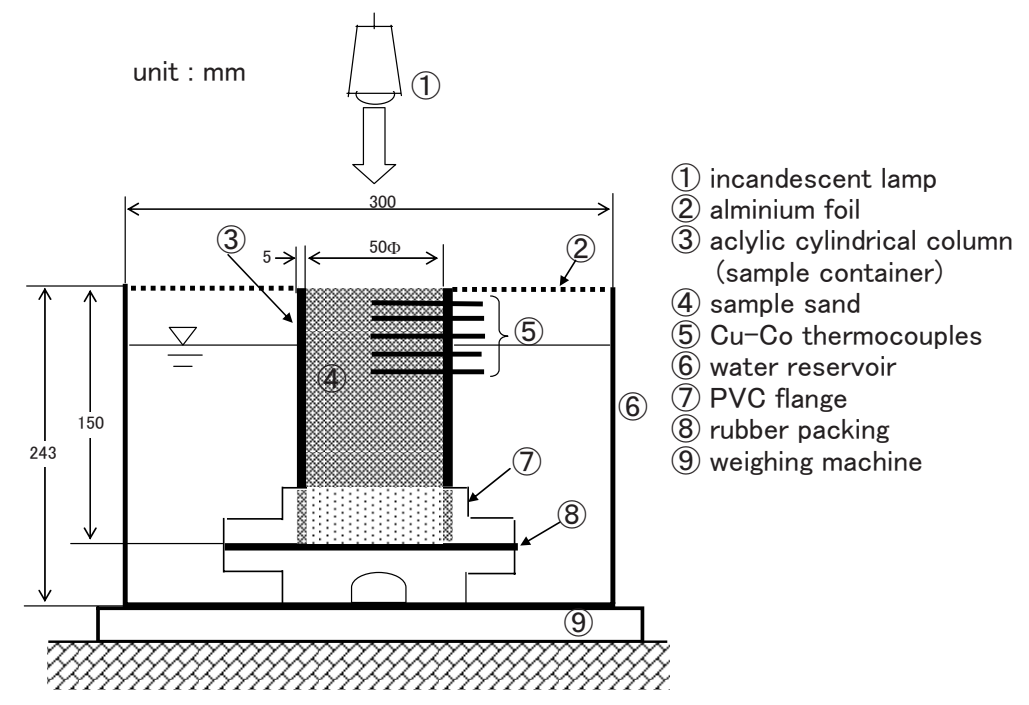

Fig. 2. Experimental apparatus. 


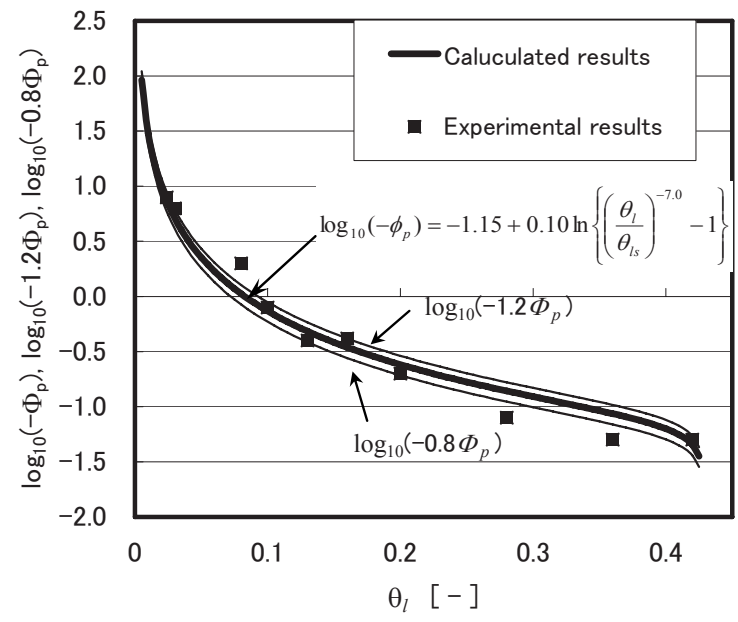

Fig. 3. Moisture characteristic curve for the sample sand.

Table 1. Experimental conditions and measured evaporation rates

\begin{tabular}{|c|c|c|c|c|c|c|}
\hline Run & $\begin{array}{c}\text { Packed } \\
\text { materials } \\
\text { (sand or air) }\end{array}$ & $\begin{array}{l}\text { Radiation } \\
\text { condition }\end{array}$ & $\begin{array}{c}\text { Outcrop height above } \\
\text { water level in a } \\
\text { water bath } l[\mathrm{~m}]\end{array}$ & $\begin{array}{c}\text { Temperature in } \\
\text { a water bath } \\
T_{l}[\mathrm{~K}]\end{array}$ & $\begin{array}{l}\text { Room temperature } \\
\text { (daily mean) } T_{a}[\mathrm{~K}]\end{array}$ & $\begin{array}{l}\text { water evaporation } \\
\text { rate at the steady } \\
\text { state }\left[\mathrm{kg} \mathrm{m}^{-2} \mathrm{~h}^{-1}\right]\end{array}$ \\
\hline 1 & sand & A & 0.1 & 300.6 & 301.2 & 1.18 \\
\hline 2 & sand & A & 0.05 & 297.9 & 298.8 & 1.06 \\
\hline 3 & sand & A & 0.01 & 296.7 & 298.2 & 0.91 \\
\hline 4 & sand & A & 0.1 & 293.9 & 295.0 & 1.31 \\
\hline 5 & sand & A & 0.05 & 292.4 & 293.0 & 0.85 \\
\hline 6 & sand & A & 0.15 & 293.2 & 294.4 & 0.43 \\
\hline 7 & sand & A & 0.12 & 293.5 & 294.4 & 0.85 \\
\hline 8 & air & B & 0 & 301.4 & 301.2 & 1.15 \\
\hline 9 & air & B & 0 & 297.9 & 298.8 & 0.94 \\
\hline 10 & air & B & 0 & 296.8 & 298.2 & 0.91 \\
\hline 11 & air & B & 0 & 294.8 & 295.0 & 0.97 \\
\hline 12 & air & B & 0 & 292.8 & 293.0 & 0.76 \\
\hline
\end{tabular}

A: radiation heat flux is $4860 \mathrm{~kJ} \mathrm{~m}^{-2} \mathrm{~h}^{-1}$ at the surface of the acrylic resin column.

$\mathrm{B}$ : radiation heat flux is $4860 \mathrm{~kJ} \mathrm{~m}^{-2} \mathrm{~h}^{-1}$ at the surface of water.

from the time when the steady state was reached until $t=76 \mathrm{~h}$ for Runs 6 and 7 , and $t=168 \mathrm{~h}$ for the other runs. In this way, the evaporation rate for the steady-state condition was obtained for the period of $t=24-76 \mathrm{~h}$ or $t=24-168 \mathrm{~h}$.

\subsection{Mathematical model}

Simultaneous heat and moisture transfer phenomena have been studied in porous materials, and many theories have been published, such as those by Philip and deVries (1957) and Hammel et al. (1981). However, no attempts have been made to apply such theories to a water recovery system equipped with porous materials. Figure 4 shows the coordinate system set for modeling.
As described above, we used a porous column of length $l_{\mathrm{t}}$ and radius $r$, into which sand was packed. Therefore, in mathematical modeling, heat loss from the side walls of the porous column must be taken into consideration in the heat balance equation.

The following assumptions are made in the modeling:

1) The porous column does not shrink or swell during the process.

2) Heat and moisture transfer occurs only in the vertical direction.

3) Since there is no forced liquid water flow, the vertical flux of the liquid water is negligible. 


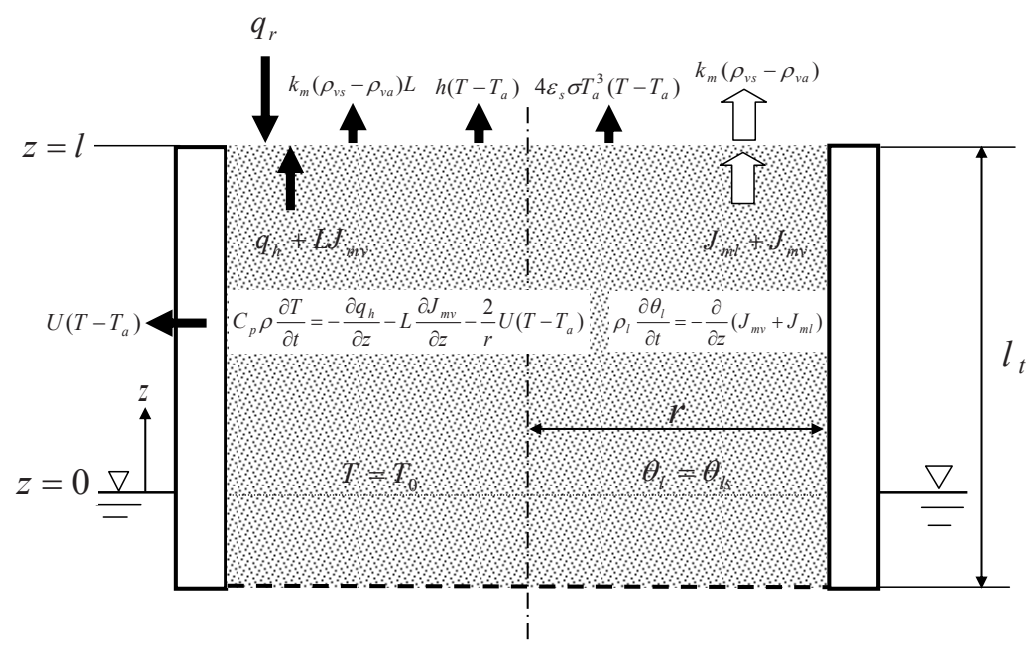

Fig. 4. Schematic representation of the heat and moisture transfer model in porous media and the coordinate system.

Therefore, the convective heat transfer flux is negligible compared with the heat conduction flux within the sand column.

4) The column packed with a porous material is saturated up to the vertical position that is equal to the water level in the water bath, $z=0$.

Under these assumptions, balance of moisture and heat in the infinitesimal region between $z$ and $z+\mathrm{d} z$ gives the following differential equations:

$$
\begin{aligned}
\rho_{l} \frac{\partial \theta_{l}}{\partial t} & =-\frac{\partial}{\partial z}\left(J_{m v}+J_{m l}\right) \\
C_{p} \rho \frac{\partial T}{\partial t} & =-\frac{\partial q_{h}}{\partial z}-L \frac{\partial J_{m v}}{\partial z}-\frac{2}{r} U\left(T-T_{a}\right)
\end{aligned}
$$

where

$\rho_{l}=$ liquid density $\left(\mathrm{kg} \mathrm{m}^{-3}\right)$

$\theta_{l}=$ volumetric moisture content $(-)$

$T=$ temperature $(\mathrm{K})$

$T_{a}=$ room temperature $(\mathrm{K})$

$L=$ latent heat of water evaporation $\left(\mathrm{kJ} \mathrm{kg}^{-1}\right)$

$U=$ overall heat transfer coefficient at the side wall of the porous column $\left(\mathrm{kJ} \mathrm{m} \mathrm{m}^{-2} \mathrm{~h}^{-1} \mathrm{~K}^{-1}\right)$

$J_{m l}=$ liquid water flux $\left(\mathrm{kg} \mathrm{m}^{-2} \mathrm{~h}^{-1}\right)$

$J_{m v}=$ water vapor flux $\left(\mathrm{kg} \mathrm{m}^{-2} \mathrm{~h}^{-1}\right)$

$q_{h}=$ heat conduction flux $\left(\mathrm{kJ} \mathrm{m}^{-2} \mathrm{~h}^{-1}\right)$

The terms $J_{m l}, J_{m v}$, and $q_{h}$ are

$$
J_{m l}=-\rho_{l} D_{T l} \frac{\partial T}{\partial z}-\rho_{l} D_{m l} \frac{\partial \theta_{l}}{\partial z}-\rho_{l} k
$$

$$
\begin{aligned}
& J_{m v}=-\rho_{v} D_{T v} \frac{\partial T}{\partial z}-\rho_{v} D_{m v} \frac{\partial \theta_{l}}{\partial z} \\
& q_{h}=-K \frac{\partial T}{\partial z}
\end{aligned}
$$

where

$D_{T l}=$ liquid water diffusivity due to the temperature gradient $\left(\mathrm{m}^{2} \mathrm{~h}^{-1} \mathrm{~K}^{-1}\right)$

$D_{m l}=$ liquid water diffusivity due to the moisture gradient $\left(\mathrm{m}^{2} \mathrm{~h}^{-1} \Delta \theta^{-1}\right)$

$k=$ unsaturated hydraulic conductivity $\left(\mathrm{m} \mathrm{h}^{-1}\right)$

$\rho_{v}=$ density of water vapor $\left(\mathrm{kg} \mathrm{m}^{-3}\right)$

$D_{T V}=$ water vapor diffusivity due to the temperature gradient $\left(\mathrm{m}^{2} \mathrm{~h}^{-1} \mathrm{~K}^{-1}\right)$

$D_{m v}=$ water vapor diffusivity due to the moisture gradient $\left(\mathrm{m}^{2} \mathrm{~h}^{-1} \Delta \theta_{l}^{-1}\right)$

$K=$ effective thermal conductivity of the porous column $\left(\mathrm{kJ} \mathrm{m}^{-1} \mathrm{~h}^{-1} \mathrm{~K}^{-1}\right)$

Table 2 shows the equations used for estimating the above transportation properties along with the references for the equations and a description of the principal parameters. Of these parameters, hydraulic conductivity $k_{\mathrm{s}}$ was obtained by the constant head permeability test in which, according to Campbell (1985), the parameter $m$ is estimated from the mean particle size of the sample sand.

The boundary conditions at the column surface are

$$
J_{m v}+J_{m l}=k_{m}\left(\rho_{v s}-\rho_{v a}\right) \quad \text { at } z=l
$$


Table 2. Equations for estimation of transport properties of the system

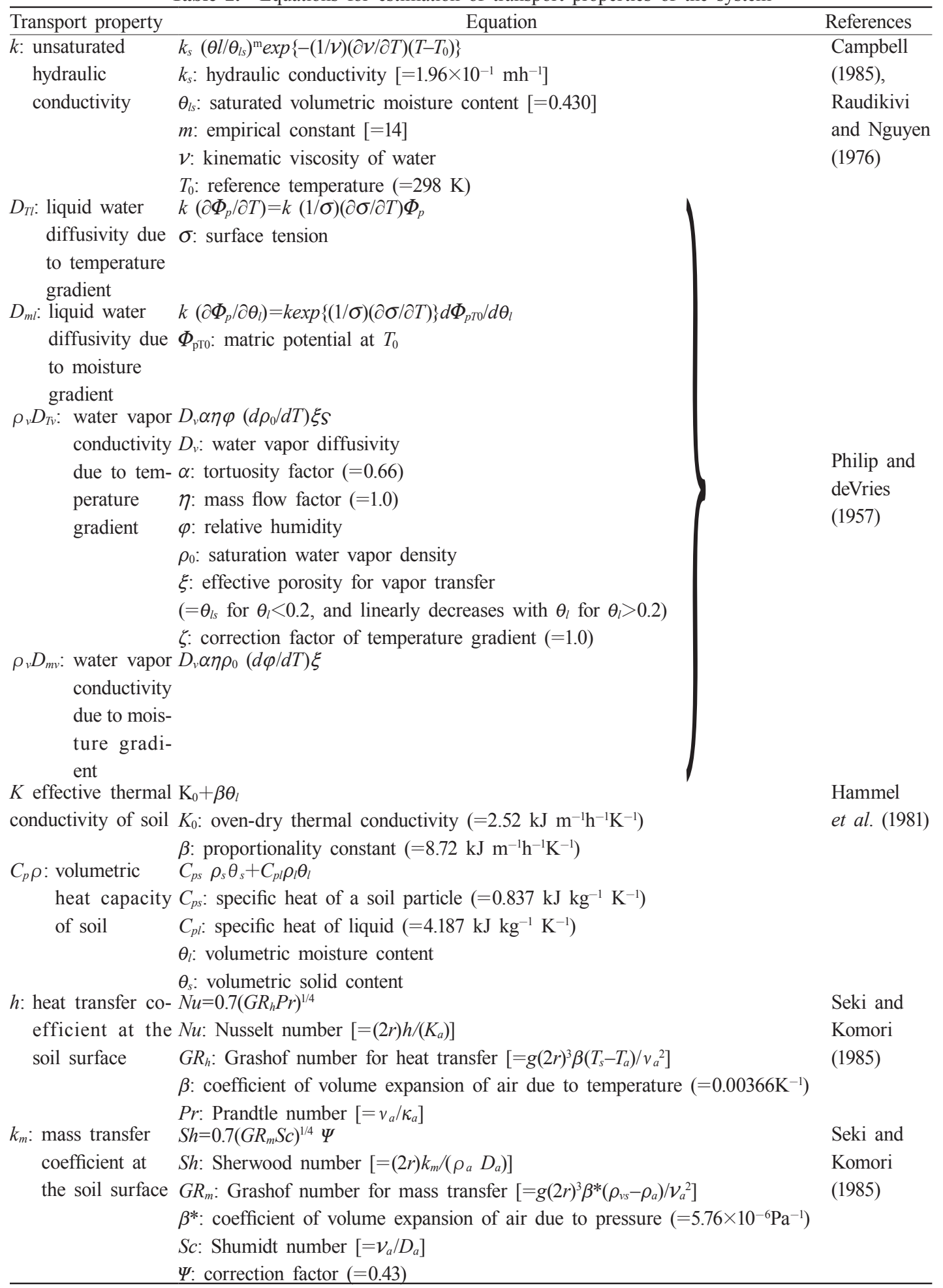


for moisture, and

$$
\begin{aligned}
& q_{h}+L J_{m v}+q_{r} \\
& \quad=\left(h+4 \varepsilon_{s} \sigma T_{a}^{3}\right)\left(T-T_{a}\right)+k_{m} L\left(\rho_{v s}-\rho_{v a}\right) \\
& \text { at } z=l
\end{aligned}
$$

for temperature,

where

$q_{r}=$ net radiative heat flux of the column surface $\left(\mathrm{kJ} \mathrm{m}^{-2} \mathrm{~h}^{-1}\right)$

$k_{m}=$ mass transfer coefficient at the column surface $\left(\mathrm{m} \mathrm{h}^{-1}\right)$

$\rho_{v s}=$ water vapor density at the column surface ( $\mathrm{kg}$ $\left.\mathrm{m}^{-3}\right)$

$\rho_{v a}=$ water vapor density of the ambient air in the room $\left(\mathrm{kg} \mathrm{m}^{-3}\right)$

$h=$ sensible heat transfer coefficient at the column surface $\left(\mathrm{kJ} \mathrm{m}{ }^{-2} \mathrm{~h}^{-1} \mathrm{~K}^{-1}\right)$

$\mathcal{E}_{s}=$ emissivity of the column surface (-)

$\sigma=$ Stefan-Boltzmann constant $\left(\mathrm{kJ} \mathrm{m}^{-2} \mathrm{~h}^{-1} \mathrm{~K}^{-4}\right)$

At $z=0, \theta_{l}$ and $T$ are constant and the boundary conditions are as follows:

$$
\begin{aligned}
& \theta_{l}=\theta_{l s} \text { at } z=0 \\
& T=T_{0} \text { at } z=0
\end{aligned}
$$

where

$\theta_{l s}=$ saturated volumetric moisture content (-)

$T_{0}=$ column temperature at the bottom of the porous column (K)

Initially, the moisture content and temperature were homogeneous:

$$
\theta_{l}=\theta_{l i}, \quad T=T_{i}, \quad \text { at } t=0
$$

In calculating the temperature and moisture content distribution, the porous column is divided into a finite number of regions of equal intervals $\Delta z$, and the differential equations and boundary conditions are rewritten into the difference form. Using the difference-form equations, $\theta_{l}$ and $T$ at the individual grid points are calculated after every small increment of time $\Delta t$ from the initial values $\theta_{l i}$ and $T_{i}$. In the numerical solution, the value of $\Delta t$ is set at $5.0 \times 10^{-6} \mathrm{~h}$, taking into consideration the stability of the numerical solutions. In actual calculations, the calculated results for $\theta_{l}$ and $T$ do not change with time after $t=24-48$ $\mathrm{h}$, as at this point, $\theta_{l}$ and $T$ are regarded as having reached steady state.

\section{Results and Discussion}

\subsection{Experimental results}

The measured rates of evaporation under the steadystate conditions are also given in Table 1. Under the same radiation conditions, the average water evaporation rate from a sand-packed column was $1.06 \mathrm{~kg} \mathrm{~m}^{-2}$ $\mathrm{h}^{-1}$, and that from a column without sand was $0.95 \mathrm{~kg}$ $\mathrm{m}^{-2} \mathrm{~h}^{-1}$. Since the water evaporation rate is higher in the former case than in the latter case, it can be concluded that the presence of sand (a porous material) effectively

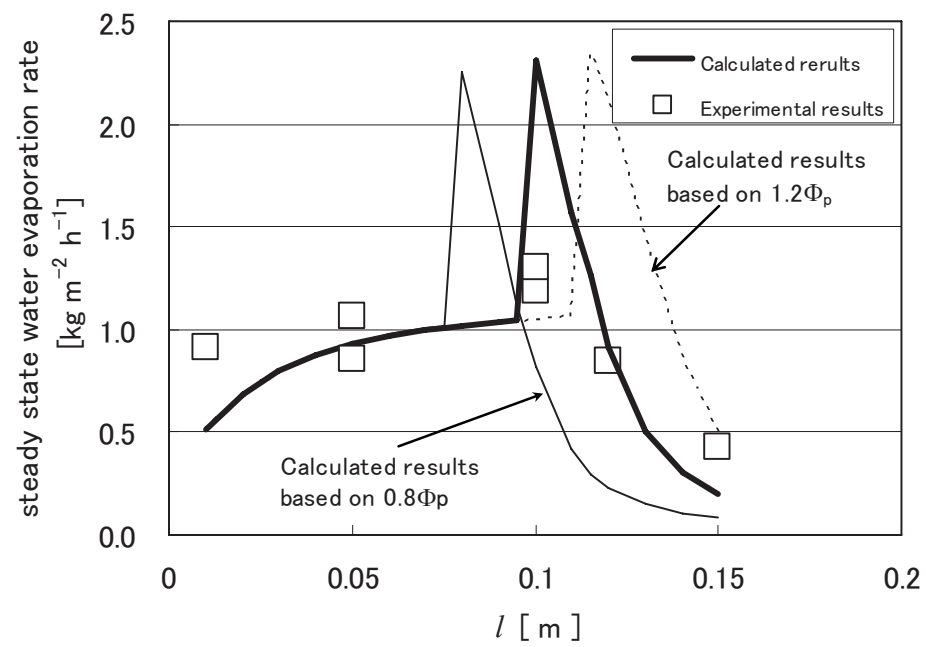

Fig. 5. Relationship between the steady-state evaporation rate and the distance $l$ between the column surface and the water level in the reservoir. 
promotes natural water recovery. The reason for this is as follows: When the column is packed with sand, the surface temperature of the sand is $11-16 \mathrm{~K}$ higher than the temperature of the water when the column does not contain sand. When the value of $l$, the distance between the column surface and the water level in the reservoir, is equal to or smaller than $0.1 \mathrm{~m}$, the moisture content at the surface is sufficient for potential evaporation, and the evaporation rate increases as the surface temperature increases.

The evaporation rate increased as $l$ increased, and reached a maximum when $l$ was about $0.1 \mathrm{~m}$ (Fig. 5). However, once $l$ had exceeded $0.1 \mathrm{~m}$, the evaporation rate gradually decreased because the volumetric moisture content at the surface decreased rapidly and potential evaporation could not be achieved. Potential evaporation occurred only when $l$ was less than or equal to $0.1 \mathrm{~m}$. This is confirmed by the fact that a completely dried layer was observed in the cases of $l=0.12$ (Run 7) and $0.15 \mathrm{~m}$ (Run 6).

Since the experiments were performed in a laboratory with no temperature control, the water temperature $T_{l}$ differed to some extent between experiments. The maximum difference was $8.6 \mathrm{~K}$. We supposed that the smaller the distance between the positions of the evaporation and water surfaces is (i.e., the smaller $l$ is), the more noticeable the effect of $T_{l}$ on the evaporation rate would be, and vice versa. In Runs 8 and 11, no sand was used, i.e., $l=0 \mathrm{~m} ; T_{l}$ was $7 \mathrm{~K}$ higher and the evaporation rate was about $20 \%$ higher for Run 8 than for Run 11. This result was as expected. Results contrary to the above supposition were observed for Runs 1 and 4 , where $l=0.1 \mathrm{~m}$. The evaporation rate was higher for Run 4 than for Run 1, although $T_{l}$ was lower for Run 4 than for Run 1. Therefore, the significance of the effect of $T_{l}$ on the evaporation rate could not be confirmed in these experiments.

\subsection{Comparison of the calculated results with the experimental results}

The calculated results for the evaporation rate from the numerical solution of the simultaneous heat and moisture transfer model in the porous medium, as described in Section 2.2, are plotted in Fig. 5. According to the calculated results, the evaporation rate gradually increases with increasing $l$, and this agrees well with the experimental results. However, at $l=0.095 \mathrm{~m}$, the evaporation rate increases sharply by 2.3 times.

For $l \approx 0.1 \mathrm{~m}$, the volumetric moisture content at the sand surface decreases rapidly because the supply of water from within the sand decreases and reaches a value of the order of $10^{-3}$. The driving force of moisture transfer, i.e., the difference in volumetric moisture content between the surface and a position just below the surface, then increases, thus, in theory, sharply increasing the evaporation rate.

For $l>0.1 \mathrm{~m}$, the water evaporation rate gradually becomes less than the potential evaporation rate, as stated in Section 3.1. This is because the completely dried layer near the surface (whose volumetric moisture content is of the order of $10^{-3}$ ) grows with increasing values of $l$.

Unlike the calculated results, the experimental results for the water evaporation rate did not increase sharply around $l=0.1 \mathrm{~m}$. The reason for this is considered to be the following: According to Fig. 3, the value of the matrix potential $\Phi_{p}$, which is one of the important factors relating to the system behavior, seems to have

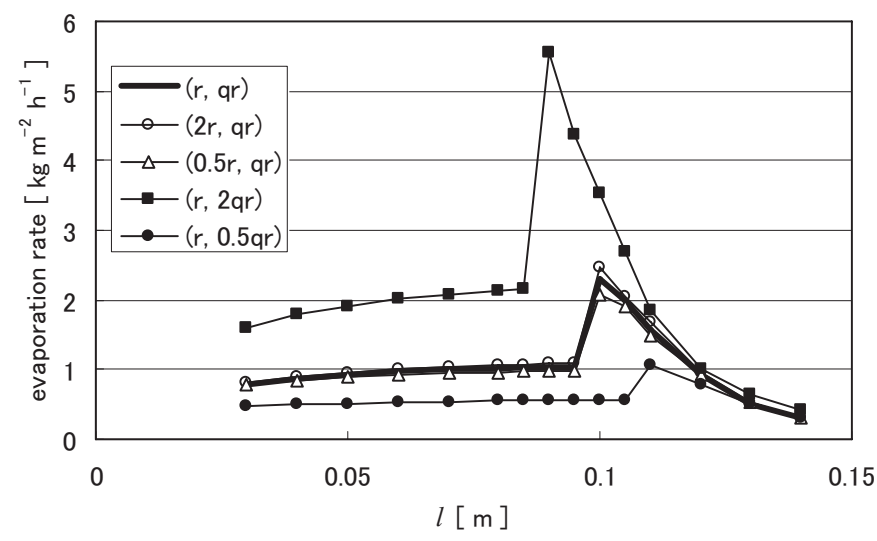

Fig. 6. Relationship between $l$ and the water evaporation rate, with $q_{r}$ and $r$ as variable parameters. 


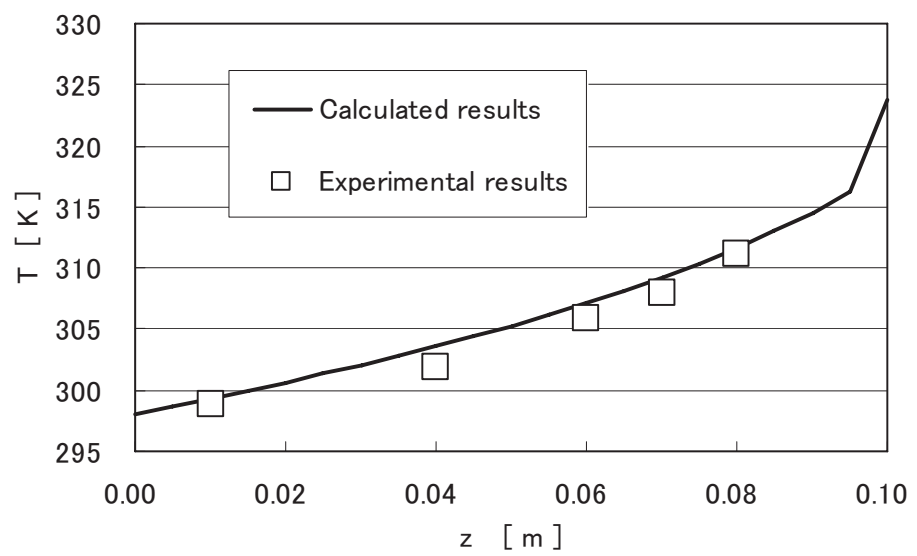

Fig. 7. Comparison between the calculated steady-state temperature distribution and the experimentally observed temperature distribution.

an error span of about $\pm 20 \%$. We therefore calculated the evaporation rate, assuming that the matrix potential is $1.2 \Phi_{p}$ or $0.8 \Phi_{p}$, and plotted the calculated results in Fig. 5. According to Fig. 5, the value of $l$ at which the maximum evaporation rate is achieved is $0.08 \mathrm{~m}$ when the matrix potential is $1.2 \Phi_{p}$, and $0.113 \mathrm{~m}$ when the matrix potential is $0.8 \Phi_{p}$. These results for $l$ differ considerably from $0.1 \mathrm{~m}$, which is the value when the matrix potential is $\Phi_{p}$. This means that the value of $l$ at which the maximum evaporation rate is achieved varies greatly with just a slight change in $\Phi_{p}$. These experimental results suggest that even if a discontinuous change in the water evaporation rate occurs locally with varying $\Phi_{p}$, the water evaporation rate, i.e., the value averaged over the entire surface area, does not change much with locally varying $\Phi_{p}$. However, we have not yet found a method for determining a proper average evaporation rate over the entire surface area and this merits future research.

Figure 6 shows the relationship between $l$ and the water evaporation rate with $q_{r}$ and $r$ as variable parameters. The value of $q_{r}$ greatly influences the water evaporation rate and the position of $l$ showing the maximum evaporation rate. If $q_{r}$ is doubled, the value of $l$ showing the maximum evaporation rate decreases, and the water evaporation rate doubles. Conversely, if $q_{r}$ is halved, the value of $l$ showing the maximum evaporation rate increases, and the water evaporation rate halves. On the other hand, a change in $r$ has little effect on both the value of $l$ showing the maximum evaporation rate and the water evaporation rate.

Figure 7 shows an example of the comparison between the calculated steady-state temperature distribution and the experimentally observed temperature distribution. The calculated and experimental results agree very well.

Summarizing the above, although the discontinuity in the evaporation rate around the maximum value could not be confirmed experimentally, there is an optimum value of $l$ showing the maximum evaporation rate, and the calculated results agree well with the experimental results for $0 \mathrm{~m}<l<0.05 \mathrm{~m}$ and $l>0.12 \mathrm{~m}$. With regard to heat transfer, the calculated and experimental temperature distributions agreed very well. Therefore, it is considered that the mathematical model for the simultaneous transfer of heat and moisture within a porous column is approximately valid.

\section{Conclusions}

As a basic study toward developing an inexpensive but effective water recovery system, experiments on water evaporation were performed using a column packed with a porous material (sand). The experimental results for the water evaporation rate and temperature profile were compared with the results calculated using a model involving simultaneous transfer of heat and moisture. The results obtained are summarized as follows:

Since the temperature of the drying front is higher for water recovery through the porous column than for direct evaporation from the water surface, the evaporation rate is higher in the former case than in the latter.

The evaporation rate depends on the distance $l$ 
between the porous column surface and the water level in the reservoir. The value of $l$ at which the evaporation rate shows a maximum was about $0.1 \mathrm{~m}$ in the experiments. This distance will vary depending on the radiative heat flux and the type of porous material.

It was concluded from the above results that a column packed with a porous material would be useful in the new water recovery system proposed here. We intend to experiment with different porous materials, select the most suitable one, and then determine the optimum value of $l$ for maximizing the evaporation rate. Furthermore, we intend to study the relationship between the evaporation and condensation rates by extending the experiment to examine the effect of using a glass cap (condenser) on water recovery.

\section{References}

Campbell, G. S., 1985: Soil Physics with Basic, Elsevier, New York, 150 pp.

Hammel, J. E., Papendick, R. I., and Campbell, G. S., 1981: Fallow tillage effects on evaporation and seedzone water content in a dry summer climate.
Soil Sci. Soc. Am. Proc., 45, 1016-1022.

Matsuoka, S., and Sohma, K., 1983: New experimental equation describing the soil moisture characteristic curves (desorption curve). Trans. JSIDRE., 104, 31-38 (in Japanese with English abstract).

Philip, J. R., and deVries, D. A., 1957: Moisture movement in porous materials under temperature gradients. Trans. Am. Geophys. Uni., 38, 222-232.

Raudkivi, A. J., and Nguyen, V. U., 1976: Soil moisture movement by temperature gradient. Proc. Am. Soc. Civil Eng., 102, GT12, 1225-1243.

Seki, H., and Komori, T., 1985: Heat and moisture loss from the soil surface heated below. Proc. Hokuriku Chapter Agric. Meteorol. Soc., 10, 67-72 (in Japanese).

Takami, S., and Inaba, H., 2000: Development of Solar Pump (1) Induction of reverse-osmosis by evaporation. Proc. Annu. Meet. Soc. Agric. Meteorol. Jpn. 460-461 (in Japanese).

Tanaka, M., Yamazaki, S., Yoshida, T., Shitamachi, T., and Takemasa, T., 2007: Development of sunlightdriven water purifier. Proc. Joint Conf. Environ. Eng. Agric. 2007, CD-ROM (in Japanese). 